\title{
Do Consumers Benefit from Supply Chain Intermediaries? Evidence from a Policy Experiment in Edible Oils Market in Bangladesh
}

\author{
M. Shahe Emran ${ }^{1}$ \\ IPD, Columbia University \\ Dilip Mookherjee \\ Boston University \\ Forhad Shilpi \\ DECRG, World Bank \\ M. Helal Uddin \\ University of Dhaka
}

This Version: January 2016

\begin{abstract}
In March 2011, Delivery Order traders (DOTs) in the edible oils market in Bangladesh were banned. The reform provides a natural experiment to test alternative models of marketing intermediaries. We develop three models and derive testable predictions about the intercept of the margin equation and pass-through of international price. A difference-in-difference analysis shows that the reform led to higher marketing margins and lower pass-through. The evidence rejects models based on pure double-marginalization-of-rents, and provision of low cost credit by DOTs, but supports a model where DOTs relax binding credit constraints faced by wholesale traders.

Keywords: Marketing Intermediary, Trader Margin, Commodity Prices, Market Power, Double Marginalization, Supplier Credit, Credit Rationing, International Prices, Passthrough, Policy Experiment, Edible Oils, Bangladesh

JEL Codes: O12, L13, Q13

\footnotetext{
${ }^{1}$ We would like to thank seminar participants at the AEA Annual Conference 2016 at San Francisco, NEUDC 2014 at Boston University, GCER Conference 2015 at Georgetown University and IGC conference at Dhaka for comments on earlier drafts and to acknowledge Wally Mullin, Chris Woodruff, Raymond Guiteras, Andrew Foster, Sabyasachi Das, Marcel Fafchamps, Sebastian Bustos, Nidhiya Menon, Wahiduddin Mahmud, Fahad Khalil and Will Martin for helpful comments on earlier drafts and/or discussions at various stages of this project. Thanks to Rubaiya Emran for help with the graphs. The project received funds from KCP Trust Fund (World Bank) and IGC Bangladesh country program. An earlier version of the paper was circulated under the title "Food Prices and Marketing Intermediaries: Evidence from a Policy Experiment in Edible Oils Market in Bangladesh". This paper supersedes the earlier version.
} 


\section{Introduction}

Throughout history, monopoly power of marketing intermediaries has been identified as one of the most important sources of high food prices; commodity speculators are often condemned as evil agents who add no value to society, but collude to raise prices and destroy the stability of the market. ${ }^{2}$ Many governments implemented measures to curb the market power of the traders, and, in some cases, banned them or particular trades they frequently make. For example, in USA Chicago onions futures were banned in 1958, which remains in place to date. Distrust of private traders led to the establishment of marketing boards in many developing countries in 1950s and 1960s. However, disappointing results with the marketing boards led to agricultural market liberalization starting from the late 1970s. Lack of trust in middlemen traders in commodity markets nevertheless remains widespread and deeply ingrained; the price spiral in international commodity markets in 2007-2008 brought their role back into focus.

Although market power among traders has been the dominant explanation for price increases in food markets among politicians and people in general, there is little rigorous evidence on the industrial organization of food markets in developing countries that can test this view. While traders may exercise market power, they may also play a variety of efficiency-enhancing roles; for example, provision of trade credit to downstream distributors, and supply assurance via inventory holdings and quality inspections, which can lower distribution costs and consumer prices. Trading off these costs and benefits requires detailed evidence-based analyses.

To this end, we study the effects of a policy reform which banned a particular layer of middlemen called the Delivery Order traders (DOTs) in the edible oils market in Bangladesh during the second half of 2011. A delivery order (DO) is a sales receipt issued by the refiner with the quantity of oil specified on it (30-45 drums of oil, each drum containing 150 maunds), to be deliverable after a specified time period. The DOTs buy the DOs from the refiners and sell them to wholesalers, usually after a period of time. The wholesalers take delivery of oil from the refiners in exchange for the DO. The government and news media identified DOTs as responsible for price rise in edible oils market by exercising undue market power. In a policy move in March 2011, DO trading was prohibited, and was replaced by a Sale Order (SO) system, whereby edible

\footnotetext{
${ }^{2}$ The sentiments were shared by most, from Aristotle to Lincoln to Lenin. For example, Abraham Lincoln said "For my part, I wish every one of them (speculators) had his devilish head shot off. (as quoted in Carpenter (1866, p. 84)), and Lenin concluded: "For as long as we fail to treat speculators the way they deserve-with a bullet in the head - we will not get anywhere at all. ((Lenin, 1964, p. 311).)
} 
oil refiners would bypass DOTs, and directly sell to newly appointed dealers among wholesale traders. We exploit this policy experiment to discriminate among alternative models of the role of marketing intermediaries.

A standard model of the vertical supply chain involving double marginalization of rents (DMR) provides a rationale for the regulation adopted by the Bangladesh Government. In this model, the pre-reform period is characterized by refiners and DOTs exerting market power, and the DOTs are pure intermediaries who do not provide any value-addition services. Elimination of the DOT layer leads to a reduction in the prices, and increases the pass-through of costs (imported crude Palm oil).

Although common in the existing theoretical literature on cost pass-through in a vertical chain (see, for example, Adachi and Ebina (2014)), the assumption that the marketing intermediaries such as DOTs do not provide any services is not consistent with the available evidence. Based on extensive and intimate knowledge of the edible oils market in Bangladesh, we develop two models where the primary role of DOTs is provision of supplier credit to the wholesale traders. In the first model, apart from exercising market power, the DOTs provide credit to the wholesalers at below-market interest rates. When DOTs are eliminated, wholesalers borrow from alternative market sources at higher interest rates, while not being subject to any credit rationing. The second model focuses on credit rationing faced by wholesale traders, and the role of DOTs is to help relax binding credit constraints. ${ }^{3}$ We show that the models deliver contrasting predictions for pass-through of crude oil prices to wholesale prices, providing an excellent opportunity to discriminate among them empirically.

The empirical analysis focuses on palm oil, which accounts for more than 75 percent of domestic edible oils consumption in Bangladesh. We use a difference-in-difference (DID) approach examining how the relation between wholesale prices of refined palm oil and import prices of crude oil differed before and after the reform, with wheat as a comparison commodity. ${ }^{4}$ The

\footnotetext{
${ }^{3}$ The DOTs do not play a significant role in quality inspection and assurance, as they do not own any storage facility and do not take physical delivery of the oil. The reputation for quality is associated with a refiner. Note that the reform reduced the search costs of the wholesale traders, as it is easier to search for better price among 9 refiners than among 300 DOTs. The fact that DOTs do not own storage capacity also implies that the ban on DOTs did not affect directly the storage capacity in the market after the reform.

${ }^{4}$ Wheat is chosen as a basis of comparison for at least three reasons. First, both wheat and palm oil are primarily imported into Bangladesh with little or no domestic production; thus the international market plays an important role in both. Second, both palm oil and wheat are easily storable, because they do not need cold storage. Third, they are bulky, necessitating substantial transport charges. Hence fluctuations in transport or
} 
availability of data before the policy intervention allows us to test the validity of the parallel trend assumption by using a placebo policy reform date. The DID design also takes into account the implications of the world market cycle, because marketing margin depends on the phase (upswing vs. downswing) of the international market, consistent with imperfect pass-through into domestic prices widely documented in the literature.

The results of the empirical analysis definitively contradict the predictions of the standard DMR model: pass-through of imported crude oil costs to wholesale prices fell significantly following the reform, while the intercept term increased. As the reform was carried out at a time of declining crude oil prices, this contributed to rising markups. Overall, controlling for the imported crude prices, wholesale prices were significantly higher following the reform, contrary to the expectations of the policy makers.

While the increased financing costs of wholesalers in the second model can explain the higher level of wholesale prices resulting from the reform, it turns out to be inconsistent with the lower pass-through observed. The third model builds in an additional role for DOTs wherein they relax credit constraints faced by wholesalers when borrowing from alternative sources. The predictions of this model are consistent with the empirical results if these credit constraints are strong enough. The intuitive explanation is that the reform sharply limited the amount of oil that wholesalers could purchase and offload onto the market, raising the price level. Pass-through of crude oil prices to wholesale prices fell as the credit limits reduced the effective price elasticity of the residual demand curve faced by refiners, thereby raising their effective market power. This explanation is also consistent with three pieces of supporting evidence: $(i)$ a decline in crude oil imports following the reform (at a time when crude oil prices were falling), (ii) survey evidence that the wholesalers had to cut back oil purchase because of credit constraint, especially during the first six months after the reform, and (iii) the fact that the reform could not be sustained beyond six months as refiners sought out previous DOTs to help relieve the supply disruptions.

This paper makes three contributions to the literature. First, it provides a test of the standard model of marketing intermediaries based on market power which underlies popular attitudes towards these intermediaries, besides being the work-horse in a large literature in industrial organization, international finance and macroeconomics. Second, it suggests that a better under-

storage costs would apply in a similar way to the distribution costs of Palm oil and wheat. One might argue that wheat is more transport and storage 'intensive' in the sense that storage and transport costs constitute a larger fraction of the price for wheat. We discuss the implications of this later in the paper. 
standing of the functioning of the commodity markets and transmission of international prices in developing countries needs to take the role of credit rationing and supplier credit seriously. Third, it provides evidence that the Bangladesh DOT ban had impacts that were the opposite of those intended by policymakers: the ban raised prices and price markups. This is important as governments in many developing countries may be considering similar anti-trader policies, driven by mistrust and misunderstanding of traders' role in the market, and reinforced by periodic price spirals in commodity markets.

Section 2 reviews related literature to place the contributions of this paper in perspective, followed by Section 3 which explains the nature of the palm oil supply chain in Bangladesh and the 2011 reform. Section 4 presents alternative models of the vertical chain in the edible oil market with a focus on the financing role of DOTs. A benchmark DMR model is used to provide a theoretical rationale for the reform. Section Section 5 develops the empirical strategy based on a difference-in-difference design, and the next section discusses the data sources. Section 7 then reports the estimates of the effects of the reform on the world-wholesale margin from the difference-in-difference design. It also provides evidence on the retail-world margin, and discusses additional evidence and an alternative explanation. Finally, Section 8 concludes.

\section{(2) Related Literature}

The theoretical and empirical analysis presented below in this paper intersects a number of important strands of economic literature. While it clearly belongs to a small but active research agenda that focuses on understanding the role of marketing intermediaries in product markets in developing countries (see, for example, Banerji and Meenakhshi (2004)), it also informs the micro foundations for pass-through of international prices to domestic consumers which has been analyzed by a large literature in international finance and macroeconomics.

The traditional focus of the theoretical and empirical literature in development economics has been on imperfections in factor markets, especially the effects of imperfect or missing credit and insurance markets. ${ }^{5}$ There is a large literature in development economics that analyzes the logic and implications of interlinked contracts in factor markets, and also across factor and product markets (see, for example, Barverman and Stiglitz (1982), Bardhan (1984)). Our analysis focuses on the role played by upstream marketing intermediaries in product market through provision

\footnotetext{
${ }^{5} \mathrm{~A}$ famous exception is Akerlof (1970), which was partly motivated by quality problems in rice market in India.
} 
of supplier credit when credit market imperfections constrain the downstream traders in the marketing chain. The transactions between the DOTs and wholesale traders can be thought of as interlinked credit and oil contracts. The fact that supplier credit is essentially interlinked credit and commodity contracts has been noted in the literature. Burkart and Ellingsen (2004) show that relative illiquidity of commodities implies that it is easier to provide trade credit compared to a pure credit contract. This argument is relevant for our application, because a DO is considerably less liquid than money, as it may not be easy for a wholesaler to find a DO buyer willing to pay cash without offering significant discounts. More important, the DOTs rely on accumulated information about the wholesalers to minimize adverse selection and moral hazard, and default information is shared quickly among the DOTs in a market, similar to multilateral punishment scheme a la Greif (1993). Information and monitoring advantages have been identified as important factors for supplier credit (see, for example, Smith (1987)).

A recent literature deals with the effects of transport infrastructure on the marketing of agricultural commodities and the prices received by the producers in developing countries (Casaburi et al. (2013), Fafchamps and Hill (2008), Minten and Kyle (1999)). In an interesting analysis, Casaburi et al. (2013) find that improvements in road quality reduced market prices of local crops in Sierra Leone, which contradicts models of bilateral bargaining, Bertrand competition, or Cournot oligopsony, but is consistent with the predictions of a search model. ${ }^{6}$ Their focus on discriminating among alternative models of intermediaries is, in spirit, similar to ours, but there are also important differences. First, Casaburi et al. (2013) rely on the the reductions in transport costs arising from road improvements as a policy experiment in specific rural areas. In contrast, the policy experiment in our application is a drastic regulation that affected the whole market. Our results are thus relevant for the country as a whole. Second, while search costs are important when farmers are trying to find better prices for their crops, as found by Casaburi et al (2013), search costs are unlikely to be an important part of the explanation in our context. As noted earlier, the policy reform we exploit reduced the search costs faced by the wholesalers, and thus our finding of an increase in the prices following the reform cannot be explained in terms of search costs. Also, search costs are likely to be very small in this market for wholesale traders, which usually involves nothing more than a couple of phone calls, and every trader owns a cell phone. Third, given that crude Palm oils are imported to Bangladesh

\footnotetext{
${ }^{6}$ They adapt the search model of Chau et al. (2009) to their application.
} 
with very little domestic production, we can ignore many possible confounding factors that can arise from domestic production shifts of a commodity.

The evidence and analysis present in this paper are relevant for a rich literature on imperfect pass-through of international prices and exchange rate variations to domestic producer and consumer prices (for recent contributions, see, among others, Goldberg and Hellerstein (2008), Nakamura and Zerom (2010), Berman et al. (2012), Bonnet et al. (2013), and for recent surveys, see Burstein and Gopinath (2013), and Campa and Goldberg (2008)). However, most of the literature focuses on developed countries, and uses the double marginalization model with pure intermediaries as the work-horse. The degree of pass-through of world prices in these models depends on two factors: the degree of market power of the marketing intermediaries in the supply chain, and the second-order curvature of the demand function (see Adachi and Ebina (2014), Weyl and Fabinger (2013)). There has also been an increasing emphasis on the role played by domestic distribution costs (transport and storage) in explaining imperfect pass-through. To the best of our knowledge, the role played by the supplier credit and, in particular, the implications of credit rationing have largely been ignored.

In an interesting paper, Atkin and Donaldson (2014) use the Bulow and Pfleiderer (1983) demand function as we do in this paper, and show that it is possible to uncover the trade costs from spatial price differences, because the pass-through rate provides a sufficient statistic for the indirect effect of a change in the trade costs on varying mark-ups. Their model differs from ours in two important ways. First, consistent with the existing literature, the traders are "pure intermediaries" in their model. The traders transport goods from the production (or import) point to a destination market incurring "trade costs" (transport costs), and the prices charged by the traders reflect both mark-ups and marginal trade costs. In our case, the DOTs play an explicit credit provision role for the downstream wholesale traders. Second, the trade costs they consider are unit costs, i.e., the costs that vary with the quantity. This is appropriate in their context where the focus is on spatial differences in prices, assuming that access to credit and interest rates do not vary significantly across locations. In contrast, our basic model incorporates both per unit (transport and storage) and advalorem trading costs (financing costs), and our focus is on average price, not its spatial heterogeneity. More important, we explore the implications of binding credit constraints faced by wholesale traders for average marketing margins and passthrough rate. 
Although there has been a renewed interest in the domestic food markets in developing countries in response to the price shocks in the international market, most studies estimate the effects of higher international prices on domestic prices (pass-through) in reduced form regressions, and the focus is usually on the implications of higher consumer prices for poverty. ${ }^{7}$ To the best of our knowledge, none of the recent studies spurred by the international price rise in 2007-2008 rigorously examined the impacts of policy interventions in the marketing chain on the marketing margin, or made an attempt to understand the role played by the intermediaries. As these types of policy interventions are being considered or implemented by other developing countries, a careful study of the Bangladesh case will be useful to the policy makers and analysts in other developing countries.

(3) The Marketing Chain in the Bangladesh Palm Oil Market and the 2011 Reform

\section{(3.1) Marketing Chain of Palm Oil Before the Policy Reform}

Here we provide a brief description of the marketing chain in the palm oil market in Bangladesh before the policy intervention in June 2011 (for a more detailed discussion, see Uddin and Taslim (2010)). The palm oil market consists of four layers: the refiners, the delivery order traders (the DOTs), the wholesalers, and retailers. The refining segment is highly concentrated, there are only 9 refiners, and observers believe that there is excess capacity (Uddin and Taslim (2010)). The refiners import crude palm oil from Malaysia and Indonesia. Most of the refined palm oil goes through the DOTs; although wholesalers can buy directly from the refiners, they have to pay cash. It is attractive for the wholesalers to buy oil from the DOTs for two reasons: $(i)$ a significant proportion of sales by DOTs to the wholesalers are on credit, and (ii) DOTs buy in bulk and get price discounts from the refiners, part of which they can share with the wholesalers. Estimates from a survey conducted by the authors in 2013 shows that about 32 percent of quantity transacted between the DOTs and wholesalers are on credit without collateral; relational credit is thus an important aspect of the marketing network.

The DOTs buy the DOs for oil deliverable by the refiner after a stipulated period of time (usually 2 weeks). It is important to appreciate that the DOTs do not own any storage, and do not take delivery of the oil. The DO layer of the market interacts vertically with the refiners

\footnotetext{
${ }^{7}$ See, for example, Ivanic et al. (2012).
} 
upstream and the wholesalers downstream, and also horizontally with other DOTs (relatively smaller DOTs buy from the large DOTs). The horizontal transactions among the DOTs have evolved into something like an embryonic commodity exchange in Moulovibazar in Dhaka and Khatunganj in Chittagong where speculators operate with the help of brokers, primarily during the upswing in the market. 8

However, note that the DO layer is not a futures market, because there is no "settlement at the end of the day (it is not marked to market). Also, unlike a futures contract, the payment is made at the time of the contract, not at the delivery date. The fact that the DOTs pay ahead of the physical delivery implies that the refiners effectively get short-term loans. Note, however, that in return for the short term loan, the refiners provide storage for the oil (the DOTs do not own any storage). Thus the cost of storage can be thought of as implicit interest rate on the short-term loan a refiner gets from the DOT. The DO is also not a standard forward contract, because the stipulated delivery date is almost never enforced. Thus the DO contract resembles something like an American call option. In some cases, a DO may not be executed for many months. This implies that the DOTs or other DO holders bear less price risk compared to a standard forward contract.

\section{(3.2) The Policy Reform}

The policy reform focused on the DO layer of the market. The law banning DO (Delivery Order) transactions and instituting SO (Sales Order) dealers in its place (i.e., Essential Commodities Marketing and Distributor Appointment Order 2011) was passed in March 232011. 90 days were allowed to implement the policy change, implying that the directive implementing the law came into effect on June 21, 2011.

It was argued by the government and popular media that in the DO system a few big players exert market power and manipulate the market by strategically buying, holding and selling DOs. Under the SO system, dealers were appointed for each "marketing area" (for example, upazilla or municipality) selected by the refiners, and a dealer is allowed to buy oil "commensurate with" the size of the market. This placed quantity restrictions on a dealer in an attempt to break the "large player" problem. ${ }^{9}$

\footnotetext{
${ }^{8}$ Our post-reform data period coincides with a downswing in the international market, and thus activities in the secondary (horizontal) DOT market were almost nonexistent.

${ }^{9}$ This also implies that the DOTs who became dealers under the new system could not buy more than a certain amount of oil.
} 
In total, 7388 dealers for edible oil were appointed by different refiners; City group, one of the largest refiners, playing a dominant role with 3796 dealers. ${ }^{10}$ A refiner was allowed to demand 200,000 taka as 'security money' for accepting a trader as its dealer, but the City Group which appointed more than half of all dealers waived the security deposit. The fact that the City Group had to waive the deposit may indicate the difficulties faced by the refiners in establishing a network of dealers to distribute the oil to the wholesalers and retailers.

The law also made the SO non-transferable, in an attempt to stop the development of lateral transactions which may become something like the embryonic organized commodity exchange under the DO-Broker system. The dealer (SO holder) is supposed to take delivery of oil from refiner within 15 days and sell it to the retailers. The requirement that the SO dealers need to take delivery of the oil implies that the dealers need storage facilities, unlike the DOTs who did not take the delivery of the oil from the refiners. ${ }^{11}$

Discussions with the traders in the two most important markets in Dhaka and Chittagong indicate that the refiners faced difficulties with the distribution of oil following the reform. Since the DOTs who became dealers after the reform did not own any storage before the reform, they faced difficulties in taking delivery of oil. More importantly, the ability to get oil from the refiners may have been limited for many dealers (wholesalers) because of a lack of credit availability. As noted above, a major function of the DOTs were that they provided oil on credit based on their accumulated information about the wholesale traders in the downstream. The reform over-night destroyed these long-standing arrangements involving interlinked credit and oil contracts.

As a result the whole sale traders turned dealers were unable to pay for the required oil, and the refiners began to accumulate stock beyond their desired level of inventory. This prompted the refiners to look for alternative distribution channels, and naturally, they went back to some of the large DOTs to sell the oil effectively undermining the new system. This meant that after approximately six months of the reform, the DOTs were able to circumvent the quantity restrictions imposed (i.e., quantity 'commensurate with' the market are served by a dealer), and the government did not take any action against it. This passivity on part of the government might have set into motion forces to push back the marketing system towards the old DO system after the first six months of the policy implementation.

\footnotetext{
${ }^{10}$ There are 9 refiners, of which the largest three serve approximately 80 percent of the market.

${ }^{11}$ One might rationalize this as an attempt to reduce hit and run entry and exit by increasing the fixed costs of operation.
} 


\section{(4) Models of the Marketing Chain}

The expressed goal of the reform was to eliminate the market power of the DOTs and was intended to reduce middlemen margins and ultimately the prices faced by the consumers. Although the government did not put forth any explicit model to justify the policy reform, a plausible model that rationalizes government's policy can be constructed where both the refiners and DOTs enjoy significant market power resulting in double marginalization and higher consumer prices.

The government's argument that the replacement of DOTs by the SOTs would result in lower prices seems plausible because the reform deconcentrated the market; the number of dealers appointed by the refiners after the reform was more than 7300, while the number of DOTs were about 300 (adding up both Dhaka and Chittagong markets). Thus purely in terms of number of dealers, the reform was successful in reducing concentration in the market. More important, most of the dealers (more than 7000) were wholesalers themselves before the reform, so it amounted to removing an intermediate layer of traders between refiners and wholesalers. A version of the model developed below captures the argument that this ought to lower middlemen margins and consumer prices.

In this section, we develop two models of the vertical chain of the edible oils market in Bangladesh where DOTs are not pure intermediaries, but provide services to the downstream wholesale traders. Although existing theoretical literature identifies a number of potential roles for marketing intermediaries including quality assurance (Biglaiser (1993)), and reduction of search costs for downstream traders and consumers (Stiglitz (1986), Chau et al. (2009)), the focus of the models below is on credit provision role of the DOTs in the oil market. This is based on empirical evidence and in-depth knowledge of the market from surveys and monitoring by the authors over the years. ${ }^{12}$ As discussed above, quality guarantee and search costs are not important in our context, and thus are not considered as alternative explanations. ${ }^{13}$

In the first model, the DOTs provide low cost credit to the wholesale traders, and the traders

\footnotetext{
${ }^{12}$ One of the authors (Helal Uddin) has been involved in research on the edible oils market in Bangladesh for more than 5 years now. All four authors were involved in monitoring the Palm oil marketing chain in Bangladesh for six months in 2013 .

${ }^{13} \mathrm{~A}$ small but growing literature has underscored the effects of cell phones on spatial price distribution in agricultural markets. For example, Fafchamps and Acker (2015) find that better access to phones reduce price dispersion, but has no effect on the average price of perishable goods. They do not find any effects on price dispersion or average price of non-perishable goods (our focus is on oils which is non-perishable). As we show below, our results are different, average price of Palm oil was affected significantly by the reform.
} 
are not credit rationed when they have to borrow from the credit market such as banks. The standard double marginalization model with pure marketing intermediaries is a special case of this model (called the 'policy model' here after) which represents a possible basis for the understanding and intent of the policy-makers. The DOTs in the second model not only provide low cost credit, they also relax binding credit constraints faced by the wholesale traders when borrowing from banks. As we shall show later, this model is new and qualitatively distinct from the standard model.

\section{(4.1) DOTs as Providers of Low Cost Credit}

We build a model of vertical chain with three layers in the market: refiners, DOTs and traders (wholesalers). Although the edible oil supply chain also includes retailers, we ignore them as the focus is on the effects of the elimination of the DOTs on wholesale prices. This simplifies the algebra. We shall assume that there are sufficiently many wholesalers that they effectively have no market power. All the conclusions would remain intact in a model that includes a competitive retail sector and the wholesalers exercise some market power. Besides, we shall see in the next section that most of the effects of the reform were on the margin between the crude import price and the wholesale price.

The inverse demand function is assumed to be that of Bulow and Pfleiderer (1983):

$$
P^{T}=\alpha-\eta Q^{\delta} ; \alpha, \eta, \delta>0
$$

where $P^{T}$ is the price charged by the traders to the consumers. There is a fixed number $\left(N_{r} \geq 1\right)$ of refiners who import crude palm oil from the world market at an exogenous price $P^{w}$ and produce edible oil with a Leontief production function; for simplicity, we assume that 1 unit of crude is transformed into 1 unit of refined oil. The refiners incur per unit cost of $C^{r}$ for labor and other intermediate inputs in addition to the crude oil cost. Refiners engage in Cournot competition; prior to the reform they sell to DOTs. The case where the refiners collude with one another is captured by a value of $N_{r}$ smaller than the true number of refiners.

There is a fixed $\left(N_{d} \geq 1\right)$ number of DOTs in the market. The DOTs buy DOs for the refined oil from the refiner at price $P^{r}$, and sell these to wholesalers. DOTs do not take physical delivery of the oil, so incur no storage or transport costs themselves. DOTs engage in Cournot competition with one another in selling DOs to wholesale traders. As with the refiners, the 
case where the DOTs collude is represented by a value of $N_{d}$ smaller than the actual number of DOTs.

Evidence from a recent survey of wholesalers and dealers indicates that an important role of the DOTs is to provide supplier credit to the wholesalers (Emran et al. (2015)). DOTs are usually quite wealthy, with access to short term capital at lower costs than is available to most wholesalers. The DOTs sell oil to the wholesale traders on credit. They bear an interest cost of $i^{d}$, smaller than $i^{b}$ which either wholesalers or refiners would bear. ${ }^{14}$

The DOTs purchase DOs from the refiners at per unit price $P^{r}$ at the beginning of the period. Upon selling DOs at price $P^{d}$ at the end of the period, the effective price received by the DOTs discounted back to the beginning of the period is $\frac{P^{d}}{1+i^{d}}$. After the reform, wholesalers buy oil directly from the refiners at the beginning of the period by taking a loan from the market at interest rate $i^{b}>i^{d}$, and they sell the oil to retailers at the end of the period. Thus they pay an effective price (inclusive of finance costs) per unit of oil equal to $P^{r}\left(1+i^{b}\right)$ after the reform. The key assumption in this version of the model is that the wholesale traders are not subject to any credit rationing. The consequence of the DOT ban is to raise the interest costs borne by suppliers, besides removing the market power of the DOT layer. The effect of the ban on wholesale prices thus depends on the relative importance of these two effects.

As mentioned above, we assume that the wholesale layer of the market is competitive, hence wholesalers have no market power and earn zero profits. Each wholesale trader incurs unit cost of $C^{T}$ for transport and storage of oil. To ensure that the market exhibit some activity, we assume that

$$
\alpha>P^{w}+C^{r}+C^{T}
$$

for if this condition were not satisfied it would be impossible for a positive quantity of oil to be supplied to consumers at a price that covers total unit costs.

The zero profit condition at the wholesaler segment implies that:

\footnotetext{
${ }^{14}$ We noted before that the up-front payments to the refiners by DOTs may be considered as short-term credit, with the effective interest rate determined by the storage costs incurred by the refiners for holding the oil before a wholesale trader takes physical delivery. We thus developed a model where the DOTs provide low interest credit to both up stream (refiners) and down stream (wholesale traders). The qualitative conclusions from such a model are, however, similar to the predictions from the model developed below with only downstream credit to wholesale traders. The details are available from the authors.
} 


$$
P^{T}=P^{d}+C^{T}
$$

Equations (1) and (3) combined gives the demand curve faced by the DOTs:

$$
P^{d}=\left(\alpha-C^{T}\right)-\eta Q^{\delta}
$$

The optimization problem of DOT $k$ facing a refiner price $P^{r}$ and given quantity chosen by other DOTs $\left(Q_{-k}\right)$ is:

$$
\operatorname{Max}_{q_{k}^{d}} \Pi_{k}^{d}=\left[\frac{P^{d}}{1+i^{d}}-\left(P^{r}+C^{d}\right)\right] q_{k}^{d}
$$

Using the inverse demand function above (see equation 1 above), the DOT optimization problem can be stated as

$$
\operatorname{Max}_{q_{k}^{d}} \Pi_{k}^{d}=\left[\frac{\alpha-C^{T}}{1+i^{d}}-P^{r}-C^{d}-\frac{\eta}{1+i^{d}}\left(Q_{-k}+q_{k}\right)^{\delta}\right] q_{k}^{d}
$$

This generates the following first order condition which is necessary and sufficient:

$$
\left[\frac{\alpha-C^{T}}{1+i^{d}}-P^{r}-C^{d}-\frac{\eta}{1+i^{d}}\left(Q_{-k}+q_{k}\right)^{\delta}\right]+q_{k}^{d} \frac{\eta \delta}{1+i^{d}} Q^{\delta-1}=0
$$

In a symmetric equilibrium, $q_{k}^{d}=q^{d}=\frac{Q}{N_{d}}$, and we obtain the following expression for the price at which wholesalers purchase DOs:

$$
P^{d}=\frac{\delta}{N_{d}+\delta}\left(\alpha-C_{T}\right)+\frac{N_{d}}{N_{d}+\delta}\left(1+i^{d}\right)\left(P^{r}+C^{d}\right)
$$

The equilibrium price is a convex combination of the demand intercept $\alpha-C_{T}$ and the unit cost $\left(1+i^{d}\right)\left(P^{r}+C^{d}\right)$ incurred by DOs (including the financing cost), where the weight on the latter which represents the rate at which cost increases are passed through to wholesalers, is increasing in the number of DOTs. As $N_{d}$ increases the DOT layer becomes more competitive, raising the pass-through rate, and lowering the level of the price paid by wholesalers (assuming inequality (2) is satisfied). The wholesale price converges to the DOT cost $\left(1+i^{d}\right)\left(P^{r}+C^{d}\right)$ as $N_{d}$ tends to infinity. Note also that the pass-through of refiner price $\left(P^{r}\right)$ or other components of unit costs such as transport and storage depends on the interest rate in this model. 
Given the way $P^{d}$ depends on $P^{r}$, we can now determine the outcome of Cournot competition among refiners. Using equations (1) and (3) above, we get the inverse demand function facing refiners:

$$
P^{r}=\left[\frac{\alpha-C^{T}}{1+i^{d}}-C^{d}\right]-\frac{\left(\delta+N_{d}\right)}{N_{d}\left(1+i^{d}\right)} \eta Q^{\delta}
$$

Hence the optimization problem for refiner $j$ is as follows:

$$
\operatorname{Max}_{q_{j}^{r}} \Pi_{j}^{r}=\left[P^{r}-\left(P^{w}+C^{r}\right)\right] q_{j}^{r}
$$

where $P^{w}$ is the world market price of crude palm oil. In a symmetric equilibrium, analogous calculations as in the case of the DOT layer yields the following expression for the price at which DOs are sold to DOTs:

$$
P^{r}=\left(\frac{\delta}{N_{r}+\delta}\right)\left[\frac{\alpha-C^{T}}{1+i^{d}}-C^{d}\right]+\left(\frac{N_{r}}{N_{r}+\delta}\right)\left[P^{w}+C^{r}\right]
$$

The equilibrium price is a convex combination of refiner cost and the demand intercept, with a cost pass-through rate which is increasing in $N_{r}$ the measure of competition at the refiner level. A higher financing cost does not affect the pass-through of world price to the price charged by the refiners, but it lowers the price level by reducing the intercept of the demand curve faced by the refiners.

The eventual outcome on the price charged by wholesalers is obtained by combining $(3,5$, 7):

$$
P_{D O}^{T}=\left[1-\frac{N_{r}}{N_{r}+\delta} \frac{N_{d}}{N_{d}+\delta}\right] \alpha+\frac{N_{r}}{N_{r}+\delta} \frac{N_{d}}{N_{d}+\delta}\left[\left(1+i^{d}\right)\left(P^{w}+C^{d}+C^{r}\right)+C^{T}\right]
$$

where $P_{D O}^{T}$ denotes equilibrium wholesale price before the reform (i.e., with DOTs operating in the market), and it is again a convex combination of the demand intercept $\alpha$ and cumulative supply cost $\left(1+i^{d}\right)\left(P^{w}+C^{r}+C^{d}\right)+C^{T}$, with a cost pass-through rate that is the product of competition measures at the refiner and DOT layers. The pass-through of world price to the wholesale price also depends on the interest rate faced by the DOTs.

After the DOT ban, the market power of the DOTs is eliminated, while the unit costs decline 
to $\left(P^{w}+C^{r}\right)$, and interest factor rises from $\left(1+i^{d}\right)$ to $\left(1+i^{b}\right)$ :

$$
P_{N D O}^{T}=\left[1-\frac{N_{r}}{N_{r}+\delta}\right] \alpha+\frac{N_{r}}{N_{r}+\delta}\left[\left(1+i^{b}\right)\left(P^{w}+C^{r}\right)+C^{T}\right]
$$

where $P_{N D O}^{T}$ is the wholesale price without the DOTs after the reform. Denoting the marketing margin between the world market and wholesale level by $M^{T}$, we have $M_{D O}^{T}=P_{D O}^{T}-P^{w}$ , and $M_{N D O}^{T}=P_{N D O}^{T}-P^{w}$. Note that the standard double marginalization model where DOTs are pure intermediaries is a special case of the above model, with $i^{d}=i^{b}=0$, which provides us with a benchmark.

A comparison of equations (8) and (9) above yield sharp predictions about the effects of the policy reform on the slope and intercept of the wholesale price. If the DOTs are pure intermediaries providing no value-addition services, the reform is expected to reduce the intercept of margin equation and increase the passthrough rate of world price $P^{w}$. The reform in this benchmark model increases competitiveness, because the term $\frac{N_{d}}{N_{d}+\delta}$ is replaced by 1 in the postreform price equation. When the DOTs provide low interest credit to the wholesale traders, the reform would increase the passthrough of crude oil price, but it can also increase the intercept if $i^{b}$ is sufficiently large compared with $i^{d}$. As a result, the level of wholesale price may go up following the elimination of DOTs from the market.

\section{(4.2) DOTs Role in Alleviating Credit Limits of Wholesalers}

In this section, we analyze a model in which the absence of DOTs following the reform led not only to an increase in the cost of borrowing by wholesale dealers, but also imposition of quantitative credit limits by alternative financiers. For simplicity, we assume that wholesalers faced no credit rationing prior to the reform, owing to long-term relationships with DOTs. The results derived below hold if the DOT provided credit is not enough to eliminate the credit constraint for some wholesale traders, as long as the trade credit relives the credit constraints substantially compared to the alternative sources such as banks.

As noted earlier, evidence from a survey conducted by the authors in 2013 indicates that about 30 percent of transactions between the DOTs and the wholesalers are on credit (32 percent of quantity). The reform constrained the use of the information capital accumulated by the DOTs (and brokers) over more than six decades. Unlike the DOTs, refiners had little or no information about the credit-worthiness of a wholesaler (dealer) and were therefore reluctant to 
provide oil on credit. ${ }^{15}$ This forced the dealers to finance their purchases from other sources, possibly resulting in binding credit limits which restricted their ability to purchase oil from refiners. The resulting disruption in oil supply to downstream retailers would then raise the price at which the wholesalers would be selling to retailers. In order to derive implications for pass-through rates, we now work out an extension of the preceding model.

Prior to the reform, we suppose the analysis of the earlier section applies, with the wholesale price determined according to (8). After the reform, wholesale dealers have to borrow at an interest rate of $\left(1+i_{b}\right)$ and are subject to a credit limit of $B$ (aggregating across all the dealers). For simplicity and tractability, we do not model the factors that give rise to credit rationing. Moral hazard ('take the money and run' as in Ghosh et al. (2001)), and difficulties in seizing collateral in the case of a default because of an antiquated and corrupt judical system may be important in the context of Bangladesh, among other things.

We assume the number of wholesalers is fixed at its pre-reform level, which is not going to be able to adjust as a consequence of the reform. As we shall see, incumbent wholesalers will end up earning positive profits following the reform owing to the oil 'shortage' which is going to emerge, which will create pressure for entry of new wholesale dealers. In the short run which seems a reasonable description of the six months for which the reform was in place - such entry may not materialize even if there are potential dealers waiting in the wings, as the process of entry can take some time to implement. It is also possible that credit constraints limit the supply of new entrepreneurs: incumbents have some access to credit to finance working capital needs, whereby potential entrants do not.

We will not, however, need any explicit notation for the number of wholesalers, as we will continue to assume that all incumbent wholesale dealers are identical and thereby focus on symmetric equilibria. We can then focus on the behavior of a single representative wholesaler that has no independent market power, and is subject to a credit limit of $B$ in value terms.

The focus on symmetric case also implies that we abstract from potential asymmetry between wholesalers who rely on trade credit and those who pay cash. This is done for the sake of tractability. One might wonder whether a model where a proportion of wholesalers are not credit rationed after the reform may yield substantially different results. Note that the wholesalers are geographically dispersed across the country, and have little or no information about the

\footnotetext{
${ }^{15}$ Recall that the wholesalers could buy oil from refiners directly before the reform, but they had to pay cash.
} 
wholesalers (and retailers) in market areas not served by them before the reform. Even if some wholesalers have excess funds after meeting the demand in their segment, they will face the same informational constraint when considering selling oil to wholesalers (retailers) from other regions who are credit rationed. More importantly, the reform imposed quantitative restrictions: a dealer could purchase oil 'commensurate with' the market area it served. Thus there can at most be some isolated cases where the wholesaler are not credit rationed given the demand curve in their local market. But as long as the proportion of wholesalers who are credit rationed is not too small, so that the credit limit $B$ is small enough, the results derived below continue to hold. In a model with spatial heterogeneity, the degree of credit rationing may vary across regions, and thus generating spatial differences in pass-through rates. In this paper, our focus is on the average prices, and we provide a discussion on whether the observed price effects of reform are consistent with the survey evidence on the extent of credit rationing (32 percent of quantity). Please see section (7.3) below.

To study when the breakdown of supplier credit arrangements can impose a binding limit on oil purchases from refiners, consider first what working capital requirements would be in the absence of any credit limit. If refiners set price $P^{r}$ and dealers borrow at interest rate $i_{b}$ after the reform without being subject to any quantitative limits, the wholesale price would be

$$
P^{T}=\left(1+i_{b}\right) P^{r}+C^{T}=\alpha-\eta Q^{\delta}
$$

as a result of competition among wholesalers. This generates the inverse demand equation faced by refiners

$$
P^{r}(Q)=\frac{\alpha-C^{T}-\eta Q^{\delta}}{1+i_{b}}
$$

implying a wholesaler working capital requirement of

$$
W(Q) \equiv Q P^{r}(Q)=\frac{Q\left(\alpha-C^{T}\right)-\eta Q^{1+\delta}}{1+i_{b}}
$$

This function is increasing over the range $Q \in\left[0, Q^{*}\right]$ and decreasing thereafter, where $Q^{*} \equiv$ $\left[\frac{\alpha-C^{T}}{\eta(1+\delta)}\right]^{\frac{1}{\delta}}$ (see Figure 1). If the credit limit $B$ is smaller than $W\left(Q^{*}\right)$, the credit limit will be binding over some range $\left(Q_{1}, Q_{2}\right)$, where $Q_{1}, Q_{2}$ are the two solutions of the equation $W(Q)=B$. 
The assumption of a binding credit limit then amounts to imposing the condition

$$
Q_{1}<Q_{u}<Q_{2}
$$

where $Q_{u}$ denotes the quantity of oil that would be purchased in equilibrium by wholesalers if they were not subject to credit rationing, i.e. is the solution to,

$$
\frac{1}{1+i_{b}}\left[\alpha-C^{T}-\eta\left(1+\frac{\delta}{N_{r}}\right) Q_{u}^{\delta}\right]=P^{w}+C_{r}
$$

Over the intermediate range $\left(Q_{1}, Q_{2}\right)$, the inverse demand function facing refiners will become a rectangular hyperbola

$$
\tilde{P}^{r}=\frac{B}{Q}
$$

instead of (11) above, thereby resulting in a change in the price elasticity of demand. This implies an interior equilibrium with credit rationing will involve quantity sold $Q_{c}$ by refiners in the interval $\left(Q_{1}, Q_{2}\right)$ which will satisfy

$$
\frac{B}{Q_{c}}\left(1-\frac{1}{N_{r}}\right)=P^{w}+C^{r}
$$

while the refiner price (using (15)) will become:

$$
\tilde{P}^{r}=\frac{N_{r}}{N_{r}-1}\left(P^{w}+C^{r}\right)
$$

This will be the unique symmetric equilibrium if

$$
\frac{B}{Q_{2}}\left(1-\frac{1}{N_{r}}\right)<P^{w}+C^{r}<\frac{B}{Q_{1}}\left(1-\frac{1}{N_{r}}\right)
$$

If this condition is not satisfied, the equilibrium will be at either corner: $Q_{1}$ if $\frac{B}{Q_{1}}\left(1-\frac{1}{N_{r}}\right) \geq$ $P^{w}+C^{r}$, and $Q_{2}$ if $P^{w}+C^{r} \geq \frac{B}{Q_{2}}\left(1-\frac{1}{N_{r}}\right)$. The above discussion assumes $N_{r}>1$, it is easy to check that if the refiner layer behaves like a monopoly, the solution is at the corner $Q_{1}$.

Note that if the credit limit $B$ is small enough, $\frac{B}{Q_{1}} \equiv \frac{\alpha-\eta Q_{1}^{\delta}-C^{T}}{1+i_{b}}$ will be large, and $\frac{B}{Q_{2}} \equiv$ $\frac{\alpha-\eta Q_{2}^{\delta}-C^{T}}{1+i_{b}}$ will be small, implying that the equilibrium will be interior. The refiner price is then given by (17), with a pass-through from $P^{w}$ to $\tilde{P}^{r}$ which exceeds unity, in contrast to the model 
without any credit rationing. The resulting price at which wholesalers sell oil is given by

$$
\tilde{P}^{T}=\alpha-\eta\left[\frac{B \frac{N_{r}-1}{N_{r}}}{P^{w}+C^{r}}\right]^{\delta}
$$

The pass-through of $P^{w}$ to the wholesale price is

$$
\frac{\partial \tilde{P}^{T}}{\partial P^{w}}=\delta \eta B^{\delta}\left[1-\frac{1}{N_{r}}\right]^{\delta} \frac{1}{\left(P^{w}+C^{r}\right)^{1+\delta}}
$$

which is small if $B$ is small. Hence the model predicts a lower pass-through rate from $P^{w}$ to the wholesale price after the reform if the resulting credit rationing is strong enough, in contrast to the models in the earlier section where the reform must increase the pass-through rate. Binding credit limits restrict the volume of oil that wholesalers can purchase; given refiners price set according to (17), we obtain

$$
Q=B\left[1-\frac{1}{N_{r}}\right] \frac{1}{P^{w}+C^{r}}
$$

which implies that the effect of higher $P^{w}$ on equilibrium quantity (and hence the price at which it is sold by wholesalers) is small when the credit limit $B$ is small.

Finally, the level of the wholesale price will approach $\alpha$ as $B$ approaches zero, so will rise as a result of the reform with sufficiently binding credit limits. Setting $P^{w}=0$ in equation (19) above, we obtain the intercept of the margin (and wholesale pricing) equation:

$$
\tilde{P}^{T}\left(P^{w}=0\right)=\left[\alpha-\eta B^{\delta}\left(1-\frac{1}{N_{r}}\right)^{\delta}\left(C^{r}\right)^{-\delta}\right]
$$

and the intercept term tends to $\alpha$ as $B$ approaches zero. So severe supply disruptions resulting from credit rationing of wholesalers can result in higher intercept and the lower pass-through rate of crude oil prices to the wholesale price, besides a lower volume of crude oil imports. The supply disruptions would cause profits of refiners to decrease as a result of the reform, since their profit margin per unit volume of oil sold $\frac{1}{N_{r}-1}\left(P^{w}+C^{r}\right)$ does not vary with the quantity sold. In fact wholesalers are the ones who profit from the disruption, as they purchase oil from the refiners at a price which does not vary with the volume of oil sold, and sell it at a price which is higher the greater the disruption (lower $B$ ). Hence an important implication of the credit rationing model is that the refiners would have a strong interest in dismantling the reform and 
bringing back the old DOTs into the supply chain.

\section{(5) Empirical Strategy}

In this section, we develop an empirical strategy for estimating the effects of the policy reform on the marketing margins. To capture the policy reform we define two dummies :

$$
\begin{aligned}
& S_{a t}=\left\{\begin{array}{c}
1 \text { if } t \geq \text { March 23, 2011 } \\
0 \text { otherwise }
\end{array} \quad\right. \text { (Announcement Effect) } \\
& S_{f t}=\left\{\begin{array}{c}
\text { if } t \geq \text { June } 21,2011 \\
0 \text { otherwise }
\end{array}\right. \text { (Implementation Effect) }
\end{aligned}
$$

We thus define three sub-periods, two following the announcement of the reform, while prereform is used as the control period. We allow for possible announcement effect because some wholesalers, retailers, and consumers may try to increase their inventory in anticipation of the reform, while the DOTs would progressively reduce their exposure to trade credit and try to collect the outstanding loans before the policy comes into effect.

As discussed above, the government allowed the refiners to go back to their large DOTs to off-load accumulating stocks after approximately six months of policy implementation. We report estimated effects of the policy reform in the short-term (up to six months after policy implementation) and long-term (after six months of policy implementation), thus dividing the post-implementation into two sub-periods. As noted before, the focus of our empirical analysis is on the effects of the policy change on the marketing margin between the world market and the wholesale traders, as the DOTs were situated in the middle.

\section{(5.1) Difference-in-Difference Approach}

\section{Choice of the Comparison Commodity and Control Variables}

As noted before, the comparison commodity chosen for our DID strategy is wheat. This choice is based on the following considerations. First, almost all of the Palm oil consumed in Bangladesh is imported from Malaysia and Indonesia; the domestic supply is virtually nonexistent. ${ }^{16}$ Similarly, wheat is also primarily imported into Bangladesh, with about 80 percent of domestic consumption met from imported wheat. Thus both palm oil and wheat are highly

\footnotetext{
${ }^{16}$ According to one estimate, there are only 500,000 palm oil trees in Bangladesh in 2011, with most of them concentrated in hill tracts of Chittagong (Rahman, 2012).
} 
dependent on international markets, and respond to the world price fluctuations. Second, palm oil and wheat are easily storable, because they are not perishable. Note that the proportion of transport and storage costs in the price of wheat is likely to be higher when compared to that in the price of palm oil. This implies that if we find that the marketing margin for palm oil has increased compared to that for wheat, it cannot be because the fuel price has gone up, or storage space has become more scarce. In the empirical analysis, we also control for the variations in the fuel price in the DID specification.

A potentially challenging issue in understanding if any observed change in the marketing margin of a commodity is due to a policy reform is that the producers may be facing increasing marginal costs when expanding production. If the marginal cost curve slopes sharply upward, a higher marketing margin may be partly due to higher marginal cost of refining when there is a positive demand shift. It is, however, extremely difficult to get the required data for estimating the marginal cost curves faced by producers (refiners in our case). Fortunately, there are good reasons to believe that it is not a first order issue in our application. First, there is excess capacity at the refiner level (Uddin and Taslim (2010)). Second, we show later that the quantity of crude imports were lower in the post reform period, thus implying that the refiners were likely climbing down the marginal cost curve. Third, the most important component of the variable cost for the refiner is the price of crude palm in the international market; when the taxes are added to the import price, the price of crude palm constitutes about 85 to 90 percent of the variable production costs (Uddin and Taslim (2010)). This also means that the cost of crude palm oil is a reliable proxy for the marginal cost faced by the refiners and movements along the marginal cost curve due to other factors may be limited at best. To be as clinical as possible, in the DID regressions, we include an indicator that captures movements along the marginal cost curve of the refiners: the relative international price of palm compared to soybean. The rationale is that the imports of palm and soybean by the refiners respond quickly to the changes in relative prices in the international market because of substitution by consumers. When the relative price of palm increases in international market, the refiners import less palm and more soybean, thus the refiner climbs down the marginal cost curve for the production of palm. For the comparison commodity wheat, we include the relative price of wheat to rice to capture the consumer substitutions. 
The above discussion leads to a DID specification of the following form:

$$
\begin{array}{r}
M_{i t}=\mu_{0}+\mu_{1} S_{a t}+\mu_{2} S_{f t}+\mu_{3} T+\mu_{4}\left(T \times S_{a t}\right)+\mu_{5}\left(T \times S_{f t}\right) \\
+\mu_{6}\left(T \times S_{a t} \times P^{w}\right)+\mu_{7}\left(T \times S_{f t} \times P^{w}\right)+\Gamma^{\prime} X_{t}+\xi_{i t}
\end{array}
$$

where $T$ is a dummy that equals 1 for palm and zero for wheat, and $X_{t}$ is a vector of time varying controls such as transport fuel price and relative price of crude palm compared to soybean in the international market. The focus of this paper is on estimating parameters $\mu_{4}$, $\mu_{5}, \mu_{6}$, and $\mu_{7}$, which are the DID estimates of the announcement and implementation of the policy reform on the intercept and slope of margin equation.

A close inspection of the data shows that the marketing margin in palm oil depends on the price trend in the international market. Figure 2 plots the world market and domestic wholesale prices of palm oil in our sample. It shows that the gap between wholesale and world prices moves counter-cyclically; the marketing margin tends to decline when the international market price is on an increasing trend, and the margin increases when the international price is on a declining path. The behavior of domestic price is consistent with widely discussed incomplete pass-through of international prices in the literature; the domestic prices do not transmit the full extent of the changes in the international market prices, both at the upswing and downswing of the international market.

This dependence of the margins on the phase of the international market makes the standard DID specification as in equation (23) above potentially misleading. For example, it is likely that a sustained increase in international price will strengthen the political resolve for a policy reform, and we are more likely to see a policy reform to be implemented after such a period of persistent price increase in the international market. This also implies that it is more likely to observe a declining international price following the policy intervention, for example, when policy is implemented at the height of the international market cycle, as was the case with the banning of DOTs in Bangladesh. Since the marketing margins increase during the downturn because of incomplete pass-through irrespective of the policy regime, one might incorrectly attribute this increase in the margins to the policy reform if one compares margins from inappropriate market phase from the pre-reform period.

We address the issue of the dependence of the marketing margins on the world price trend 
in two ways. First, we include a dummy that takes on 1 when the international price is rising. Second, and more important, for the "before sample", we identify a time period that matches closely the international market phase observed after the policy intervention, and exclude the observations from the other pre-intervention periods. This strategy uses a subset of the preintervention sample, but is clearly more satisfactory in dealing with the counter-cyclical margins issue.

\section{(6) Data}

Several data sets are utilized in the empirical analysis. The daily price data come from the Department of Agricultural Marketing (DAM) unit of Ministry of Agriculture. The Trading Corporation of Bangladesh (TCB) also reports daily price data from major urban centers. We compared daily price data from both sources. The price trends in both data sets are nearly indistinguishable. The price data from DAM however are available for one additional year (2008) compared with the TCB data. Moreover DAM reports price data for a wider range of commodities compared to TCB. We thus use the DAM data for our empirical analysis. The daily international price data of wheat are derived from the data stream of Chicago Board of Trading. ${ }^{17}$ Crude palm oil price data are taken from the Malaysian Palm oil Board. Lentil import unit values are taken from the National Bureau of Revenue daily import data. Our sample extends from January 24, 2008 to October 4, 2012. There are however some data gaps due to lack of price data during weekends and holidays as well as some missing data in the DAM original data set. Our total sample sizes for most commodities (palm oil and wheat) are 966 days spread over 57 months.

To provide a feel of the data used in the analysis, Table A.1 in the online appendix reports summary statistics for the prices and the margins for palm oil and wheat during pre and postreform periods. For palm oil, the world-wholesale margin, the focus of our analysis, has increased in the post-reform period. In contrast, the margin has declined for wheat marketing in the postreform period. In the following, we present the estimates of the policy effect on the marketing margin from formal econometric analysis.

\footnotetext{
${ }^{17}$ Crude palm oil was listed in the TCB in January 2009. We compared TCB data with MPB data on daily palm oil prices, there are again nearly identical.
} 


\section{(7) Results from the DID Analysis}

In this section, we present the empirical evidence from the difference-in-difference design. ${ }^{18}$ The focus of our econometric analysis is on the world-wholesale trading margin, as this segment of the vertical chain contains the DOT layer of the market. We, however, also report estimates of the effects of the reform on world-retail trading margin in a subsection later. We define the trading margin using alternative measures of crude oil costs. We report two sets of results, using the same-period and two week lagged values of world crude price as the relevant costs. The choice of two weeks lag is motivated by the fact that it takes about two weeks to transport crude oil from Malaysia and Indonesia. The estimates, using one week lagged crude price, for example, are very close to the estimates using two weeks lagged crude price (available from the authors).

\section{(7.1) Evidence on the Validity of the DID Design}

We provide evidence on the validity of the DID design with two tests of the parallel trend assumption between palm and wheat margins. First, we report graphical evidence on the behavior of palm and wheat margins in the pre-reform sample. Figure 3 plots the marketing margins (world to wholesale) for palm and wheat for the pre-intervention sample; the marketing margin for wheat tracks the changes in the marketing margin for palm well (the phase of the market, and most of the peaks and the troughs). This is reassuring for the DID design. We present additional evidence on the evolution of trading margins for palm oil and wheat over the pre-reform sample period in an online appendix (please see figures A.1- A.4b in online appendix).

As a more formal test of the parallel trend assumption we use a placebo policy implementation date that splits the the pre-reform sample (before the enactment of the law in March 23 of 2011). If the DID identifying assumption is violated, we should find significant DID effect for the fictitious policy reform date. For this exercise, we take the matched pre-intervention sample, and divide it roughly into two halves. We then define a policy intervention dummy which takes a value of unity during the first half of the sample and zero otherwise. We then estimate the effect of this placebo policy intervention on palm trading margins (wholesale and retail). The results are reported in Table 1. The placebo policy dummy and its interactions with palm dummy and world crude price are not statistically significant at the conventional level for both worldretail and world-wholesale margins, and the estimated effects are small in magnitude. Taken

\footnotetext{
${ }^{18}$ The empirical results from a before-after approach are reported in the online appendix. The estimates are consistent with the conclusions reached on the basis of DID analysis below.
} 
together, the evidence is strong evidence in favor of the identifying assumption required in the DID analysis.

\section{(7.2) Estimates of the Effects of Reform on Wholesale Margin and Pass-through}

We start with a correlogram analysis of the prices which indicates the presence of an AR (1) process in the residuals. All regressions in this paper thus correct standard errors for the presence of AR(1) in residuals as well as heteroskedasticity using the Newey-West (1987) procedure. The results presented in the following used one period lag as indicated by correlogram analysis but the central conclusions of this paper are robust to inclusion of higher order lags. The null hypothesis of unit root in the residual is rejected at the 1 percent level for all of the margin regressions.

Table 2 presents the results from the DID estimation for three different samples, called "full", "restricted" and "matched" samples. The restricted sample defines the pre-reform period as the two preceding years. ${ }^{19}$ A close inspection of crude palm prices at the world market identifies one matching sample period during the pre-reform period. Consistent with post intervention price trends, prices in 2008 and the first half of 2009 continued to decline from a high in early 2008. The "matched sample" thus takes out the period of palm price rise in the international market from the pre-intervention sample. Since the margins become smaller in upswing phase of the international market reflecting imperfect pass-through, a point discussed earlier, a preintervention sample that includes such a phase can potentially bias the estimated policy effects upward, especially because there is no similar sustained increase in international price in the post-intervention sample. We thus believe that the estimates from the matched sample are the most credible.

Panel A reports the estimates when traders margin at time $t$ is estimated using the same period $(t)$ crude price as the relevant cost, while panel B reports the corresponding estimates when two weeks lagged crude price is used to calculate trader's margin. ${ }^{20}$ The specification in the odd columns of Table 2 controls for only year and quarter dummies, and that in even columns adds a set of controls discussed above in the empirical strategy section. ${ }^{21}$ Regardless of the

\footnotetext{
${ }^{19}$ This is motivated by the argument that, in a standard DID design, observations closer to the reform date may yield more reliable estimates.

${ }^{20}$ The two week lag is motivated by the fact that it takes about two weeks to transport crude palm oil from Malaysia to Bangladesh. The results are similar if we use one week lagged crude price as the cost, and thus those estimates are omitted for the sake of brevity.

${ }^{21}$ For an extended discussion on the role played by the control variables, please see the discussion on the results from the before-after approach in the online appendix.
} 
sample and the set of controls used, the results in Table 2 suggest statistically and numerically significant and positive effects of policy implementation on the intercept of the world-wholesale margin equation. The effects on the slope of wholesale margin with respect to crude oil price is consistently negative and statistically significant at the 1 percent level. These conclusions about the effects on the intercept and slope of wholesale margin are robust; the estimates are broadly similar in magnitudes across Panels A and B in Table 2. The effect of policy announcement is, in contrast, not robust; the conclusions depend on how we calculate trader's margin, and the choice of comparison sample. If we focus on the matched sample, the effects are not statistically significant at the 10 percent level for both the intercept and slope when the same period crude price is used to calculate trader's margin. The results for margins based on two weeks lagged crude price are very different, the effects are both numerically large and statistically significant at the 1 percent level. What is most striking about the results in Table 2 is the robust conclusion that instead of reducing the marketing margin, the implementation (and possibly announcement) of the reform actually increased it, contrary to the expectation of the policy makers. The evidence on the effects of policy implementation on the slope of the margin equation in Table 1 shows that the passthrough of crude oil price into wholesale price fell after the policy reform, because the absolute value of the slope was larger after the reform. ${ }^{22}$

The evidence in Table 2 thus contradicts both the pure intermediary model of double marginalization of rents and the financing costs model without any credit rationing. The evidence is consistent with the predictions from a model where the DOTs enhance the efficiency of intermediation in the marketing chain by relaxing binding credit constraints faced by the wholesale traders.

The estimates in the last column of Panel A of Table 2 imply that the wholesale price in the post reform period was 5.18 percent higher as a result of higher intercept of margin equation and lower passthrough following the reform. The corresponding estimates from the estimates in Panel B of Table 2 (using two weeks lagged crude price) imply that the wholesale price experienced a 5.42 percent increase after the implementation of the reform, and a 9.3 percent increase in the period between announcement and implementation. ${ }^{23}$

\footnotetext{
${ }^{22}$ The pass through rate is given by (1 - absolute slope of trader's margin w.r.t world crude oil price).

${ }^{23} \mathrm{We}$ do not calculate the announcement effect on prices for Panel A, as the estimates are not significant in the matched sample.
} 


\section{(Un)sustainability of the Reform}

In this sub-section, we examine if the effects of policy intervention changes overtime. We divide the post implementation sample into two parts: the 'short-term' sample consists of the first six months period after the policy implementation and the 'long-term' is the rest of the postreform sample. We define a dummy which takes the value of unity during the first 6 months following implementation date (June 21, 2011). Coefficient of this dummy (interacted with palm dummy) captures the immediate effects of implementation. To capture the 'long term' effect, we define another dummy which takes the value of unity for the rest of the period after first 6 months and zero otherwise. We repeat our estimation with these new policy variables using the matched sample, as this is likely to provide the most credible estimate of the effects of reform. The regression specification used is the same as that in even columns in Table 2, including the full set of controls. The results are reported in columns (1) and (2) of Table 3.

The evidence shows that the effect of policy reform on wholesale trading margin is much stronger during the first six months of the implementation of the reform when compared to the average estimates presented earlier in Table 2. After six months, the effects become statistically insignificant and numerically small according to the estimates based on two week lagged crude price as the measure of trader's costs (see column (2) in Table 3). The estimated effects after six months based on the same period crude price are significant at the 1 percent level, but the numerical magnitudes are much smaller, less than one third of the estimates for the first six months. The wholesale price was 7.9 percent higher on an average in the first six months of the post reform period because of the supply disruption caused by the reform, and it was 3.4 percent higher after first six months (using the estimates in column (1) of Table 3). As noted above, the effect of the reform is insignificant after six months according to the estimates using two weeks lagged crude price in column (2) of Table 3.

The results in Table 3 thus suggest that the effects of the policy reform eliminating the DOT layer of the market on the intercept and slope of wholesale trading margin were much stronger during the first six months of implementation of the reform. This is consistent with the discussion before that in the face of perverse effects of the reform, the dealers were not taking oil delivery which most likely reflects the credit constraint faced by them, and as a result the refiners went back to large DOTs. The government also chose not to enforce the 'SO Law' that banned the DOTs. Our results show that after approximately six months, the wholesale market 
largely reverted back to the old DOT system. As we discuss below in section (7.4), the evidence that the reform could not be sustained is important in discarding an alternative explanation for the effects of the reform based on increased market power of refiners following the reform.

\section{(7.3) Estimated Effects on the Consumer (Retail) Prices}

The focus of our analysis has been on the margin between wholesale and world market because the reform eliminated the DOT layer which was situated in between them. In this section, we report estimates of the effects of the reform on consumer (retail) prices. The comparison sample from pre-reform period is the "matched sample". We report estimates for world-retail margin calculated using both the same-period crude price (odd columns) and the two week lagged crude price (even columns) as the relevant cost. The first two columns report estimates from a specification similar to the last column in Table 2, and the lat two columns report the estimates from the specification that separates out the short and long term effects as in Table 3.

The evidence reported in Table 4 is broadly similar to the effects we found earlier for the wholesale price; the reform increased the retail price by increasing the intercept of the margin equation and lowering the pass-through of world price, as predicted by the credit rationing model. The estimates in the last two columns again show that the reform could not be sustained, the effects became numerically much smaller (less than half) and/or insignificant after six months of the implementation date. However, the important point here is that the fact that reform had a positive effect on the intercept, but a negative effect on the slope contradicts the models based on double marginalization and DOTs providing low cost finance without any credit rationing.

The consumer (retail) price in the post reform period was 8.3 percent higher on an average according to the estimated effects on slope and intercept of retail margin in column (1) of Table 4 , and 8 percent higher according to column (2). The effect is much smaller after first six months of the reform: the consumer prices was 11 percent higher in the first six months, and 6.6 percent higher after six months, according to the estimates in column (3).

\section{(7.4) Additional Evidence and Discussion}

The theory and evidence presented so far in this paper contradict the widely held view that marketing intermediaries are the cause of higher market prices in edible oils market in Bangladesh, and suggest that they provide valuable services to the wholesale traders by relaxing binding credit constraints. In this section, we provide additional evidence that supports this 
conclusion. If the wholesalers faced difficulties in buying oil from the refiners because of lack of credit, then the refiners would not be able to sell the expected volume of oil consistent with a declining world price, and consequently cut back the imports of crude Palm oil as they accumulate excessive inventory. Based on case studies of two refiners, Nurjahan Group and Bangladesh Edible Oils Limited, Choudhury and Clara Costa (2012) report that, immediately after the reform, the demand for oil by the dealers was exceptionally low, and the refiners were unhappy with the reform.

Choudhury and Clara Costa (2012) provide evidence that these two refiners reduced imports of crude Palm oil significantly following the implementation of the reform in June $2011 .{ }^{24}$ More important, the evidence indicates that the reform reduced aggregate imports of crude Palm oil. Since imports are lumpy and there may not be any imports in some weeks of a month, we aggregate the data at the monthly frequency. The estimate from before-after comparison using simple OLS regression shows that the implementation of the reform had a significant negative effect on the crude oil imports (a coefficient of -20.73 , significant at the 5 percent level). ${ }^{25}$ This is striking evidence because one would have expected higher imports in the post reform period when the refiners move down along the demand curve with falling costs of crude oil.

Although the quantity of imports went down, it does not necessarily follow that the refiners were adversely affected by the reform. If the reform increased the market power of the refiners (for example, if they were better able to coordinate and collude), then the reduction in quantity may reflect a move towards the monopoly quantity after the reform. In fact, a simple alternative explanation of the increase in prices and weakening of passthrough after the reform is that the DOT layer of the market was competitive before the reform, and the reform facilitated monopoly practices among the refiners. If this alternative model is correct, then the refiners would try to protect their monopoly profit by cooperating with the government to make the ban on DOTs permanent. In contrast, the model based on credit rationing faced by the wholesalers when DOTs were banned implies that the refiners earn lower profit after the reform, because per unit profit of refiners does not depend on the quantity sold (see equation (17) above). The evidence in Table 3 that the effects of the reform on the intercept and slope of the wholesale margin equation became small or statistically insignificant after first six months of the implementation

\footnotetext{
${ }^{24}$ They report that crude oil import by these two refiners in 2010 was 417,000 MT, but in 2011 the import drastically dropped to $254,000 \mathrm{MT}$, implying a 39 percent reduction in volume.

${ }^{25}$ The monthly import data is not adequate to do a formal DID analysis.
} 
of the reform supports the conclusion that the market was reverting back to the old DOT system after the first six months of the reform. Interviews with the refiners by the authors in 2013 and 2016 confirm that they were unhappy with the reform, and surreptitiously went back to the DOTs to offload their accumulated inventory, as the dealers were reluctant to take oil delivery. A retrospective survey of 50 wholesale traders in Dhaka by the authors conducted in February of 2016 also corroborates this conclusion. According to the survey, the wholesale traders gradually went back to the DOTs starting from after 3 months of the implementation of the reform. Taken together, different pieces of evidence strongly suggest that the refiners' profit was adversely affected by the reform, consistent with the prediction of the credit rationing model.

An important piece of evidence comes from a survey the authors conducted in 2013 in the edible oils market in Bangladesh (Emran et al. (2015)). Based on the data on 6176 transactions between DOTs and wholesalers in Dhaka and Chittagong markets, an estimated 30 percent of the transactions between DOTs and wholesalers is on credit. In terms of quantity, the supplier credit from the DOTs accounted for 32 percent of the volume. Thus credit provided by the DOTs to the wholesale traders plays a vital role in the market. Although 32 percent of the quantity at the wholesale level are financed by the DOTs, we would expect the reduction in quantity to be lower than 32 percent after the reform, as the wholesalers seek out alternative credit sources presumably at higher interest rates. To the best of our knowledge, there is no reliable estimate of price elasticity of Palm oils in Bangladesh. A recent estimate of price elasticity of palm oil for USA at the wholesale level is -1.24 (Kojima et al. (2014)). Since a large part of demand for palm oil comes from the poor households in rural Bangladesh, we would expect that price elasticity would be larger in magnitude. The available estimate at at the household level for India is -1.62 (Srinivasan (2005)). If we assume that the price elasticity of Palm Oil at the wholesale level in Bangladesh is approximately -2.00, then a 5 percent increase (using estimates from Table 2) in wholesale prices would require a 10 percent reduction in quantity, implying that the wholesale traders were able to find alternative sources of credit for the remaining 22 percent of the quantity on suppliers credit under the DOTs. To get a sense of the quantity adjustments by the wholesalers after the reform, we asked retrospective questions to the 50 wholesalers in Dhaka surveyed in February 2016 noted above. The estimates from the survey show that, among the wholesalers who used to take oil from DOTs on credit before the reform, quantity of oil fell by 
45 percent during the first six months after the reform. This would imply that these wholesalers were not able to arrange credit from alternative sources for about half of the quantity (about 15 percent of the total quantity), implying a price elasticity close to -3.00 , with a 5 percent increase in the price. The evidence taken together thus suggests that the breakdown of the long-term credit arrangements resulted in approximately 15 percent reduction in the quantity of oil at the wholesale level, and about 5 percent increase in wholesale price in the post reform period because of the supply disruption.

\section{(8) Concluding Comments}

There is a widely held view that the presence of marketing intermediaries in commodity markets ends up raising consumer prices, owing to the effects of their market power in the supply chain exceeding the value of cost-reducing distribution services they provide. The Bangladesh 2011 policy experiment provides a rare opportunity to test this view, as it attempted to eliminate an entire layer of such intermediaries. Using high frequency data for the prices of imported crude besides wholesale and retail prices of refined oil relative to wheat which is also imported in bulk and incurs similar storage and transport costs, we showed that the reform increased the average margin between the crude import and the wholesale price. In particular the data firmly rejects the predictions of the standard double marginalization model which formalizes the hypothesis that the presence of intermediaries with significant market power who do not provide concomitant distribution-cost-reducing services ends up raising consumer prices. The model predicts the reform should have lowered the intercept and increased the pass-through rate of the crude oil price to wholesale prices, whilst the precise opposite was observed.

An extension of the basic double marginalization model to allow the intermediaries to provide cost-reducing services (such as financing dealers at below-market interest rates) is also incapable of explaining the lower pass-through of imported crude prices observed following the reform. This suggests the DOTs played a more fundamental role in the supply chain. One possible role is alleviating credit limits that wholesalers are subjected to when borrowing from alternative sources. Such credit rationing could have severely disrupted volumes in the supply chain, resulting in higher average wholesale prices and lower pass-through rates from imported crude prices. Note that this does not deny the possibility that the DOTs exercised significant market power. The point is that the consequences of such market power were outweighed by their financing role within the supply chain. 


\section{References}

Adachi, T and T, Ebina (2014), "Cost Pass-Through and Inverse Demand Curvature in Vertical Relationships with Upstream and Downstream Competition", Economics Letters, Vol.124, No.3 (September 2014), pp.465-468.

Aristotle, S., (1988). The Politics. Cambridge University Press, Cambridge, MA.

Atkin, D and D. Donaldson (2014), Whos Getting Globalized? The Size and Implications of Intra-national Trade Costs, Working paper.

Banerji, A., Meenakshi, J.V. (2004), Buyer Collusion and Efficiency of Government Intervention in Wheat Markets in Northern India: An Asymmetrical Structural Auction Analysis, American Journal of Agricultural Economics, 86(1): 236-253.

Bardhan, Pranab K. (1984). Land, Labor, and Rural Poverty: Essays in Development Economics. Delhi: Oxford University Press/New York: Columbia University Press.

Bardhan, Pranab K.(1980). "Interlocking Factor Markets and Agrarian Development: A Review of Issues". Oxford Economic Papers 32.1 (1980): 8298.

Berman, N., P. Martin, and T. Mayer (2012): "How do different exporters react to exchange rate changes?", Quarterly Journal of Economics, 127, pp. 437492.

Biglaiser, G (1993), "Middlemen as Experts", Rand Journal of Economics, Summer 1993.

Bonnet, C., P. Dubois, S. Villas-Boas, and D. Klapper (2013): "Empirical evidence on the role of nonlinear wholesale pricing and vertical restraints on cost pass-through", Review of Economics and Statistics, Vol. 95, No. 2, pp. 500515.

Braverman, A and J. Stiglitz (1982), "Sharecropping and the Interlinking of Agrarian Markets". American Economic Review, 72, 695-715.

Burkart, M, and T. Ellingsen (2004), "In-Kind Finance: A Theory of Trade Credit", American Economic Review, June 2004.

Burstein, A., and G. Gopinath (2013): 'International prices and exchange rates', Handbook of International Economics, Volume IV, Elsevier

Carpenter, F., 1866. Six Months at the White House with Abraham Lincoln. Hurd, New York. Casaburi L., Rachel Glennerster and Tavneet Suri (2013), Rural Roads and Intermediated Trade: Regression Discontinuity Evidence from Sierra Leone, Working paper, Stanford University. Chau, Nancy H \& Goto, Hideaki \& Kanbur, Ravi, 2009. "Middlemen, Non-Profits and Poverty," CEPR Discussion Papers 7459, C.E.P.R. Discussion Papers. 
Emran, M. S, D. Mookherjee, F Shilpi, and H. Uddin (2015), Trading Margins and Contracts in a Vertical Marketing Chain: Evidence from Edible Oils Market in Bangladesh, Working Paper, World Bank.

Fafchamps, M, \& Ruth Vargas Hill (2008). "Price Transmission and Trader Entry in Domestic Commodity Markets," Economic Development and Cultural Change, University of Chicago Press, vol. 56, pages 729-766.

Ghosh, P, D. Mookherjee, and D, Ray (2001), Credit Rationing in Developing Countries: An Overview of the Theory, in Mookherjee, D and D. Ray ed. Readings in the Theory of Economic Development, Wiley, 2001.

Goldberg, P., and R. Hellerstein (2008): A structural approach to explaining incomplete exchangerate pass-through and pricing-to-market, American Economic Review, Vol. 98, No. 2, pp. 423-429.

Ivanic, M. and W. Martin, and H. Zaman, 2012. Estimating the Short-Run Poverty Impacts of the 2010i $i \frac{1}{2} 11$ Surge in Food Prices, World Development, Elsevier, vol. 40(11), pages 2302-2317. Kojima, Y, J. Parcell, J. Cain (2014), A Demand Model of the Wholesale Vegetable Oils Market in the U.S.A, Working paper.

Lenin, V.I., 1964. Complete Collected Works, vol. 35. Moscow.

Minten, Bart \& Kyle, Steven, 1999. The effect of distance and road quality on food collection, marketing margins, and traders' wages: evidence from the former Zaire, Journal of Development Economics, Elsevier, vol. 60(2), pages 467-495, December.

Nakamura, E., and D. Zerom (2010): Accounting for Incomplete Pass-Through, Review of Economic Studies, Vol. 77, No. 3, pp. 1192-1230.

Smith, J K (1987), Trade Credit and Informational Asymmetry. Journal of Finance, September, 1987, 42(4), pp. 86369.

Srinivasan, P V (2005), Impact of Trade Liberalization on Indias Oilseed and Edible oils sector, IGIDR, Working Paper.

Uddin, H and M. Taslim (2010), An Assessment of Competition in the Edible Oil Market of Bangladesh, Bureau of Economic Research, University of Dhaka, Bangladesh.

Weyl, E. G., and M. Fabinger (2013): Pass-Through as an Economic Tool: Principles of Incidence under Imperfect Competition, Journal of Political Economy, Vol. 121, No. 3, pp. 528- 583. 
Table 1: Test of Parallel Trend: Effects of Fictitious Policy Implementation

\begin{tabular}{lcccc}
\hline & \multicolumn{2}{c}{ Wholesale Margin } & \multicolumn{2}{c}{ Retail Margin } \\
\hline & $\begin{array}{l}\text { Same Period } \\
\text { Prices }\end{array}$ & $\begin{array}{l}\text { 2 Weeks Lagged } \\
\text { Crude Price }\end{array}$ & $\begin{array}{l}\text { Same Period } \\
\text { Prices }\end{array}$ & $\begin{array}{l}\text { 2 Weeks Lagged } \\
\text { Crude Price }\end{array}$ \\
\hline Placebo Policy Dummy (PPD) & -0.946 & 2.028 & -1.819 & 2.110 \\
& $(-0.386)$ & $(0.386)$ & $(-0.798)$ & $(0.414)$ \\
PPD * Palm Dummy & -1.399 & -10.67 & 4.693 & -1.879 \\
& $(-0.324)$ & $(-1.325)$ & $(1.182)$ & $(-0.255)$ \\
PPD* Palm Dummy * World Price & 0.0209 & 0.140 & -0.0732 & 0.0183 \\
& $(0.380)$ & $(1.325)$ & $(-1.411)$ & $(0.188)$ \\
Observations & 626 & 480 & 626 & 480 \\
\hline
\end{tabular}

Notes: (1) ' $t$ ' statistics are in parenthesis. (2) Odd columns report estimates where the same period world market price of crude palm oil is used to calculate trading margins, and the even columns for the case when two weeks lagged crude price is used. (3) The regressions include year, quarter, product fixed effects, relative prices, a dummy for upswing in the world market, Ramadan dummy and fuel price (diesel).

Table 2: Effects on Wholesale-World Margin

\begin{tabular}{|c|c|c|c|c|c|c|}
\hline & \multicolumn{2}{|c|}{ Full Sample } & \multicolumn{2}{|c|}{ Restricted Sample } & \multicolumn{2}{|c|}{ Matched Sample } \\
\hline & (1) & $(2)$ & $(\mathbf{1})$ & $(2)$ & (1) & $(2)$ \\
\hline Effects of Announcement & \multicolumn{6}{|c|}{ Panel A (Same period crude price) } \\
\hline Intercept & $\begin{array}{r}\mathbf{3 5 . 2 5}^{* *} \\
(2.285)\end{array}$ & $\begin{array}{l}\mathbf{2 4 . 6 8 *} \\
(1.675)\end{array}$ & $\begin{array}{r}\mathbf{3 7 . 7 2}^{* *} \\
(2.415)\end{array}$ & $\begin{array}{l}\text { 24.71* } \\
(1.685)\end{array}$ & $\begin{array}{r}32.27 * * \\
(2.094)\end{array}$ & $\begin{array}{r}\mathbf{2 2 . 3 6} \\
(1.514)\end{array}$ \\
\hline Slope & $\begin{array}{r}-\mathbf{0 . 3 1 2} \\
(-1.629)\end{array}$ & $\begin{array}{r}-\mathbf{0 . 2 2 1} \\
(-1.214)\end{array}$ & $\begin{array}{r}-\mathbf{0 . 3 1 1} \\
(-1.605)\end{array}$ & $\begin{array}{r}-\mathbf{0 . 2 3 2} \\
(-1.279)\end{array}$ & $\begin{array}{r}-\mathbf{0 . 3 1 2} \\
(-1.630)\end{array}$ & $\begin{array}{r}\mathbf{- 0 . 1 8 9} \\
(-1.030)\end{array}$ \\
\hline Effects of Implementation & & & & & & \\
\hline Intercept & $\begin{array}{r}25.62 * * * \\
(7.503)\end{array}$ & $\begin{array}{r}21.10 * * * \\
(5.591)\end{array}$ & $\begin{array}{r}\mathbf{2 7 . 5 2} * * * \\
(7.857)\end{array}$ & $\begin{array}{r}19.88 * * * \\
(4.934)\end{array}$ & $\begin{array}{r}25.95 * * * \\
(7.435)\end{array}$ & $\begin{array}{r}\mathbf{2 6 . 8 8}^{* * * *} \\
(6.603)\end{array}$ \\
\hline Slope & $\begin{array}{r}-\mathbf{0 . 2 3 2} * * * \\
(-5.333)\end{array}$ & $\begin{array}{r}-\mathbf{0 . 2 1 0} * * * \\
(-4.445)\end{array}$ & $\begin{array}{r}-\mathbf{0 . 2 2 4} * * * * \\
(-5.011)\end{array}$ & $\begin{array}{r}-\mathbf{0 . 2 1 1} * * * * \\
(-4.301)\end{array}$ & $\begin{array}{r}-\mathbf{0 . 2 7 3} * * * \\
(-6.078)\end{array}$ & $\begin{array}{r}-\mathbf{0 . 2 8 1} * * * * \\
(-5.385)\end{array}$ \\
\hline Observations & 1,932 & 1,932 & 1,374 & 1,374 & 1,312 & 1,312 \\
\hline Effects of Announcement & \multicolumn{6}{|c|}{ Panel B ( 2 weeks lagged crude price) } \\
\hline Intercept & $\begin{array}{r}\mathbf{8 7 . 3 2} * * * \\
(6.632)\end{array}$ & $\begin{array}{r}\mathbf{8 1 . 6 8}^{* * * *} \\
(6.007)\end{array}$ & $\begin{array}{r}94.15 * * * \\
(6.990)\end{array}$ & $\begin{array}{r}\mathbf{8 6 . 6 3} * * * \\
(6.193)\end{array}$ & $\begin{array}{r}\mathbf{8 0 . 6 4} * * * \\
(6.100)\end{array}$ & $\begin{array}{r}82.95 * * * \\
(5.456)\end{array}$ \\
\hline Slope & $\begin{array}{r}-\mathbf{0 . 9 6 5 * * *} \\
(-5.853)\end{array}$ & $\begin{array}{r}-\mathbf{0 . 9 2 0} * * * \\
(-5.427)\end{array}$ & $\begin{array}{r}-\mathbf{1 . 0 2 9} * * * * \\
(-6.125)\end{array}$ & $\begin{array}{r}-\mathbf{0 . 9 7 9} * * * * \\
(-5.642)\end{array}$ & $\begin{array}{r}-\mathbf{0 . 9 0 3} * * * * \\
(-5.432)\end{array}$ & $\begin{array}{r}-\mathbf{0 . 9 2 9} * * * * \\
(-4.844)\end{array}$ \\
\hline Effects of Implementation & & & & & & \\
\hline Intercept & $\begin{array}{r}\mathbf{2 3 . 2 4} * * * \\
(6.886)\end{array}$ & $\begin{array}{r}\text { 16.21**** } \\
(4.190)\end{array}$ & $\begin{array}{r}\mathbf{2 1 . 8 1} * * * \\
(6.770)\end{array}$ & $\begin{array}{r}17.48 * * * \\
(4.825)\end{array}$ & $\begin{array}{r}25.65 * * * \\
(7.334)\end{array}$ & $\begin{array}{r}23.96 * * * \\
(4.478)\end{array}$ \\
\hline Slope & $\begin{array}{r}-\mathbf{0 . 2 1 4} * * * \\
(-4.786) \\
\end{array}$ & $\begin{array}{r}-\mathbf{0 . 1 4 8} * * * \\
(-3.091) \\
\end{array}$ & $\begin{array}{r}-\mathbf{0 . 1 7 4} * * * \\
(-4.212) \\
\end{array}$ & $\begin{array}{r}-\mathbf{0 . 1 6 3} * * * \\
(-3.729)\end{array}$ & $\begin{array}{r}-\mathbf{0 . 2 6 5} * * * \\
(-5.629) \\
\end{array}$ & $\begin{array}{r}-\mathbf{0 . 2 4 1} * * * \\
(-3.441) \\
\end{array}$ \\
\hline Observations & 1,904 & 1,904 & 1,374 & 1,374 & 1,284 & 1,284 \\
\hline
\end{tabular}

Notes: (1) 't' statistics are in parenthesis. All regressions include year, quarter and product fixed effects. (2) Slope denotes the slope of wholesale margin with respect to world crude oil price. (3) Regressions in even numbered columns include relative prices, a dummy for upswing in the world market, Ramadan dummy and fuel price (diesel). 
Table 3: Sustainability of the Reform

\begin{tabular}{lrr}
\hline & \multicolumn{2}{c}{ Wholesale-World Margin } \\
\hline & Same Period Prices & Two Weeks Lagged Crude Price \\
Announcement Effects & $\mathbf{2 4 . 0 5}$ & $\mathbf{8 2 . 4 7 ^ { * * * }}$ \\
INTERCEPT & $(1.622)$ & $(5.536)$ \\
& $\mathbf{- 0 . 2 1 0}$ & $\mathbf{- 0 . 9 2 0 * * *}$ \\
SLOPE & $(-1.141)$ & $(-4.897)$ \\
\hline Effects of Policy Implementation & & \\
Effects during first 6 months & & $\mathbf{4 1 . 2 3 * * *}$ \\
INTERCEPT & $\mathbf{6 6 . 9 9 * * *}$ & $(4.904)$ \\
& $(8.692)$ & $\mathbf{- 0 . 4 5 2 * * *}$ \\
SLOPE & $\mathbf{- 0 . 8 1 3 * * *}$ & $(-4.029)$ \\
\hline Effects after first 6 months & $(-7.677)$ & $\mathbf{8 . 6 1 7}$ \\
INTERCEPT & & $(1.436)$ \\
& $\mathbf{1 3 . 4 3 * * *}$ & $\mathbf{- 0 . 0 6 4 8}$ \\
SLOPE & $(3.394)$ & $(-0.847)$ \\
\hline
\end{tabular}

NOTES: (1) 't' statistics in parenthesis. $* * *$ denotes significant at the 1 percent, $* *$ at the 5 percent, and $*$ at the 10 percent level. (2) Slope denotes the slope of wholesale margin with respect to world crude oil price. (3) The first column report estimates where the same period world market price of crude palm oil is used to calculate trading margins, and the second column for the case when two weeks lagged crude price is used. (4) The regressions include year, quarter, product fixed effects, relative prices, a dummy for upswing in the world market, Ramadan dummy and fuel price (diesel). 
Table 4: Effects on Retail-World Margin

\begin{tabular}{|c|c|c|c|c|}
\hline & \multicolumn{2}{|c|}{$\begin{array}{l}\text { Average Effects in Post- } \\
\text { reform Sample }\end{array}$} & \multicolumn{2}{|c|}{ Sustainability of Reform } \\
\hline & $\begin{array}{r}\text { Same Period } \\
\text { Prices }\end{array}$ & $\begin{array}{l}2 \text { Weeks } \\
\text { Lagged }\end{array}$ & $\begin{array}{r}\text { Same Period } \\
\text { Prices }\end{array}$ & $\begin{array}{l}2 \text { Weeks } \\
\text { Lagged }\end{array}$ \\
\hline \multicolumn{5}{|c|}{ Announcement Effects } \\
\hline INTERCEPT & $\begin{array}{c}\mathbf{2 7 . 2 2} \\
(1.462)\end{array}$ & $\begin{array}{c}\mathbf{7 3 . 6 0} * * * \\
(3.990)\end{array}$ & $\begin{array}{c}\mathbf{2 7 . 9 2} \\
(1.494)\end{array}$ & $\begin{array}{c}\text { 73.11*** } \\
(4.033)\end{array}$ \\
\hline SLOPE & $\begin{array}{r}-\mathbf{0 . 2 4 5} \\
(-1.066) \\
\end{array}$ & $\begin{array}{c}\mathbf{- 0 . 8 1 5} * * * \\
(-3.517) \\
\end{array}$ & $\begin{array}{r}-\mathbf{0 . 2 5 4} \\
(-1.099) \\
\end{array}$ & $\begin{array}{c}\mathbf{- 0 . 8 0 7} * * * \\
(-3.541) \\
\end{array}$ \\
\hline \multicolumn{5}{|c|}{ Effects of Policy Implementation } \\
\hline INTERCEPT & $\begin{array}{c}37.29 * * * \\
(10.36)\end{array}$ & $\begin{array}{c}\mathbf{2 6 . 3 6} * * * \\
(5.667)\end{array}$ & & \\
\hline SLOPE & $\begin{array}{c}\mathbf{- 0 . 3 8 1} * * * \\
(-8.171) \\
\end{array}$ & $\begin{array}{c}-\mathbf{- 0 . 2 4 4} * * * \\
(-4.016) \\
\end{array}$ & & \\
\hline \multicolumn{5}{|c|}{ Effects during first 6 months } \\
\hline INTERCEPT & & & $\begin{array}{c}\mathbf{7 0 . 3 8}^{* * * *} \\
(12.04)\end{array}$ & $\begin{array}{c}\text { 41.16**** }^{* *} \\
(5.739)\end{array}$ \\
\hline SLOPE & & & $\begin{array}{c}-\mathbf{0 . 8 2 7} * * * \\
(-10.29) \\
\end{array}$ & $\begin{array}{c}-\mathbf{0 . 4 2 3} * * * \\
(-4.426) \\
\end{array}$ \\
\hline \multicolumn{5}{|c|}{ Effects after first 6 months } \\
\hline INTERCEPT & & & $\begin{array}{c}\text { 30.39**** } \\
(7.491)\end{array}$ & $\begin{array}{c}\text { 11.81** } \\
(2.539)\end{array}$ \\
\hline SLOPE & & & $\begin{array}{c}-\mathbf{0 . 2 9 8} * * * \\
(-5.931) \\
\end{array}$ & $\begin{array}{r}\mathbf{- 0 . 0 7 8 1} \\
(-1.304) \\
\end{array}$ \\
\hline
\end{tabular}

NOTES: (1) ' $t$ ' statistics in parenthesis. *** denotes significant at the 1 percent, ${ }^{* *}$ at the 5 percent, and $*$ at the 10 percent level. (2) Slope denotes the slope of margin with respect to world market crude oil price. (3) The first column report estimates where the same period world market price of crude palm oil is used to calculate trading margins, and the second column for the case when two weeks lagged crude price is used. (4) The regressions include year, quarter, product fixed effects, relative prices, a dummy for upswing in the world market, Ramadan dummy and fuel price (diesel). 
Figure 1

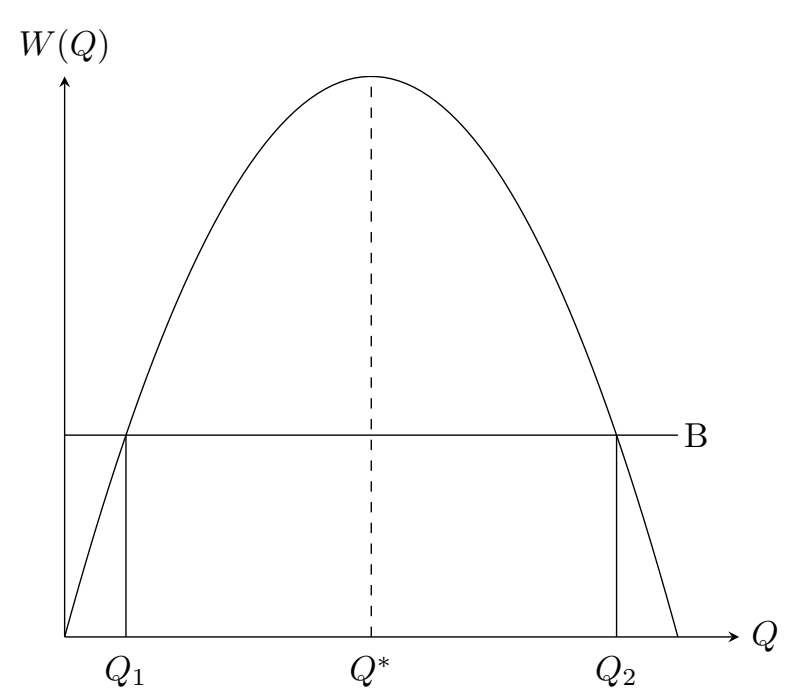


Figure 2: World and Wholesale Prices: Palm oil

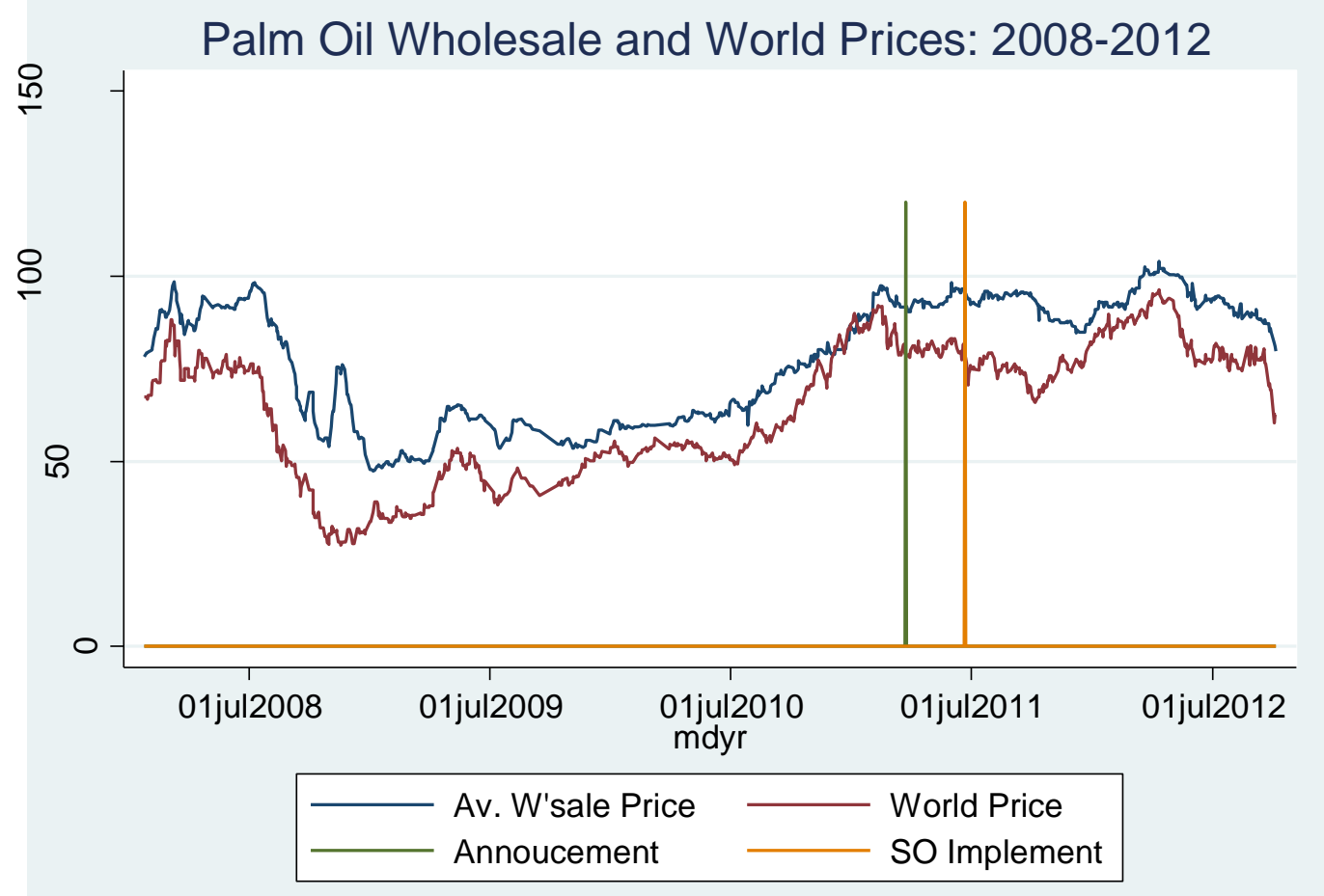

Figure 3: World -Wholesale Trading Margins: Palm and Wheat (Current Crude Price)

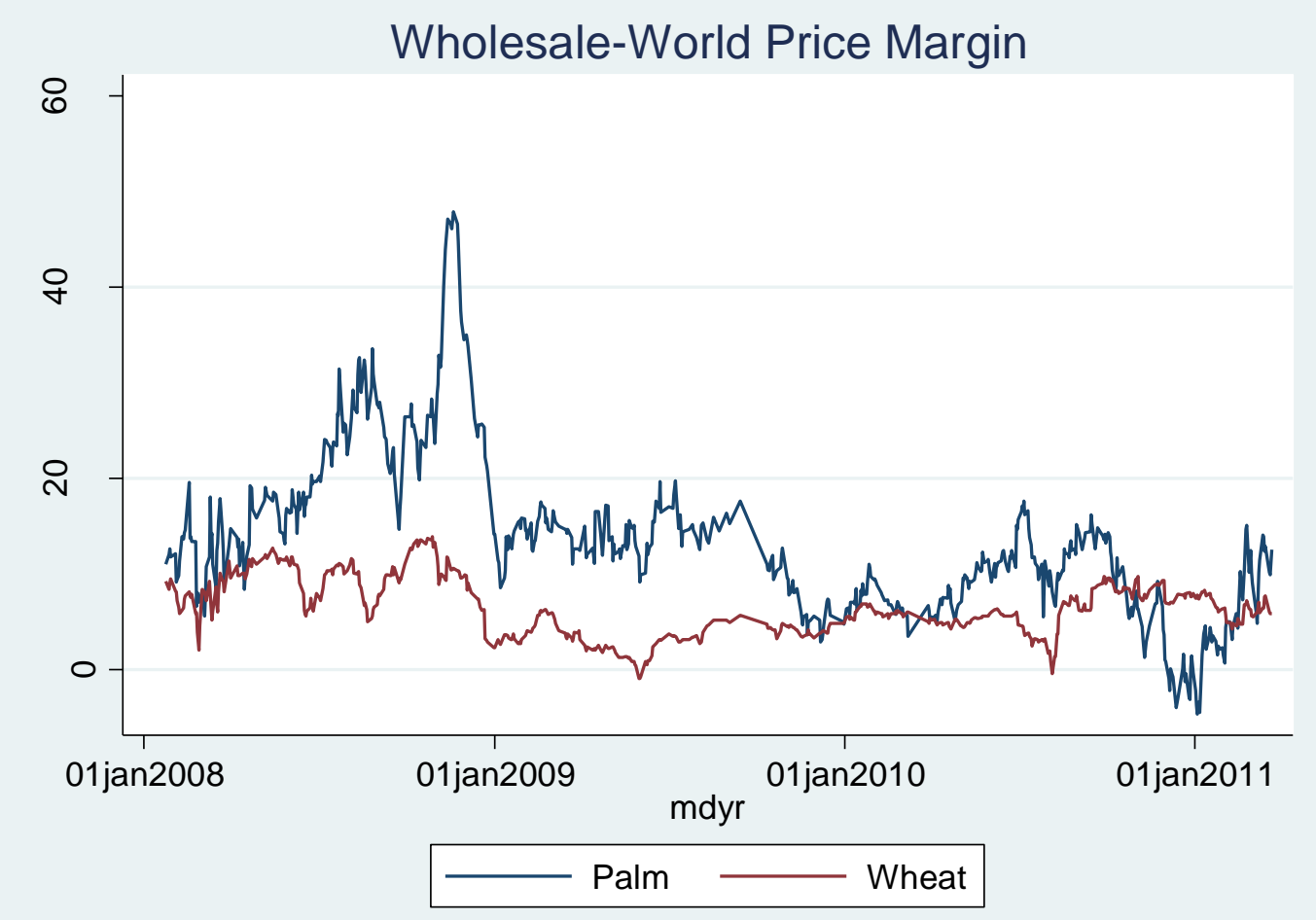


Figure 4: World and Wholesale Price Margins: Palm and Wheat (2 week lagged crude price)
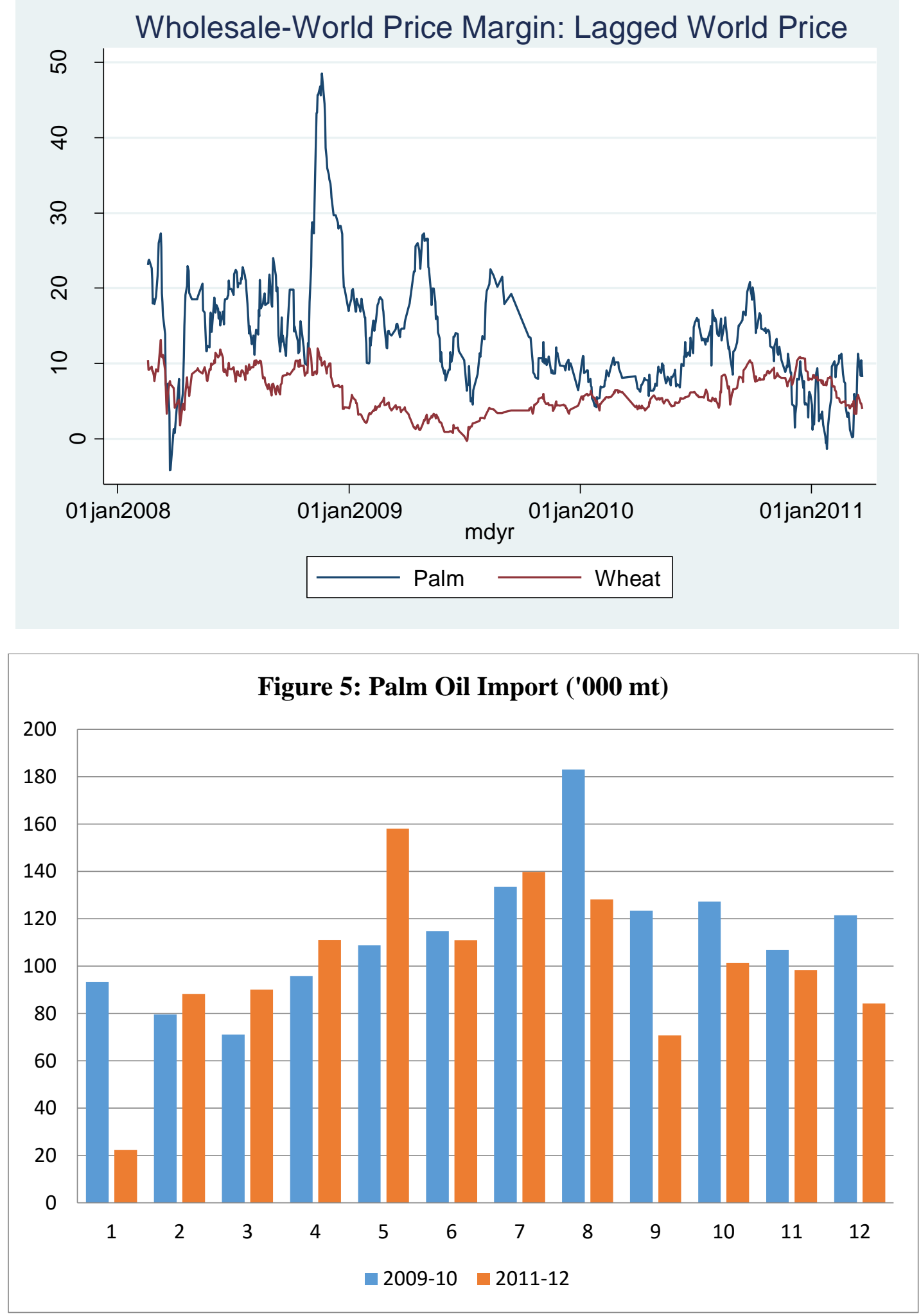